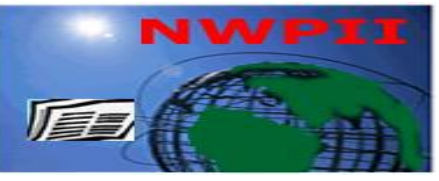

American Journal of Biomedical Sciences

ISSN: 1937-9080

nwpii.com/ajbms

\title{
Sero-reactivity and Molecular Studies on Subjects with Malaria Immunity and Susceptibility in An Endemic Region
}

\author{
"Abdulazeez Aderemi ABUBAKAR1 PhD, FMLSCN, Sulaiman Adebayo NASSAR² Ph.D, Temidayo \\ Daniel ADENIYI ${ }^{3}$ PhD, FMLSCN, Olubisi Janet SOLADOYE ${ }^{3}$ B.MLS.
}

$1^{1 *}$ Dr. Abdulazeez Aderemi ABUBAKAR,Department of Medical Laboratory Science,University of Medical Sciences , Ondo-City Nigeria.Email: aabubakar@unimed.edu.ng, Tel:+2348068039485

${ }^{1}$ Dr. Temidayo Daniel ADENIYI,Department of Medical Laboratory Science, University of Medical Sciences, OndoCity, Nigeria.Email: dtemidayo@unimed.edu.ng,Tel: +2348030612404

${ }^{2}$ Dr. Sulaiman Adebayo NASSAR,Department of Biomedical Sciences, College of Health Siences,LAUTECH,Osogbo, Nigeria.Email: sanassar@lauthec.edu.ng, Tel: +2348053274453

${ }^{3}$ Mrs Olubisi Janet SOLADOYE,Department of Medical Laboratory Science,Achievers University, Owo, Nigeria. Email: abuazeez1962@gmail.com, Tel: +2348094768849

\section{"Corresponding Author}

Dr. Abdulazeez Aderemi ABUBAKAR

Department of Medical Laboratory Science

University of Medical Sciences

Ondo-City

Nigeria

Email: aabubakar@unimed.edu.ng

Tel:+2348068039485

Received:04 March 2019; | Revised:19 March 2019;| Accepted: 10 September 2019

\begin{abstract}
Nigeria is a malaria-endemic country, yet many inhabitants of the country rarely suffer from the disease in spite of regular exposures to the vector of Plasmodium and without administration of curative or prophylactic drug. The aim of the study was to identify the subjects with resistance against malaria and conduct serological and genomic investigations their unique blood samples. One thousand two hundred and seventy $(1,270)$ apparently healthy volunteers, aged 16-55 years participated in the study. Malaria distribution among the subjects was assessed by microscopy and serology techniques using six millilitres of the blood samples withdrawn from the subjects and questionnaire administered. Subjects with resistance against malaria were identified, their blood sera collected, tested, titrated and graded. Molecular analysis of the blood samples with respect to Fc gamma receptor IIa was conducted on malaria resistant and susceptible subjects. . The study revealed $21.0 \%$ malaria infection rate by microscopy, $40.3 \%$ by serology method while $21.0 \%$ was assessed to develop natural resistance against malaria infection. Genomic analysis of blood samples from malaria resistant individuals depicted greater association with R/R131 (36.7\%). The study revealed that some individuals in this locality are genetically and immunologically protected against malarial infection. Further studies on the specific genes and immunoglobulins responsible for their uniqueness are recommended.
\end{abstract}




\section{Introduction}

In Africa, malaria accounts for $10 \%$ of the total disease burden while transmission occurs in about 107 countries globally ${ }^{[1-4]}$. It also accounts for 30 to $50 \%$ in-patients and up to $50 \%$ out-patients in highly endemic areas and about $40 \%$ of public health expenditure is spent on malaria annually ${ }^{[5-7]}$. In Nigeria, malaria is a common disease and it posed a serious public health problem ${ }^{[8,9]}$.

Although the disease is preventable and curable, its related deaths account for up to $11 \%$ of maternal mortality, $25 \%$ of infant mortality and $30 \%$ of under-five mortality ${ }^{[10-12]}$ resulting in about approximately one million deaths annually. In the regions where malaria is rampant, $85 \%$ of the infection usually effects children below 5 years and the prevalence is high amongst expectant mother ${ }^{[13}$, 14].

Malaria remains a serious global challenge in view of its high mortality rate and economic burden despite all efforts to roll it back by over 100 countries of the world $[15,16]$. In Nigeria, malaria constitutes a major public health issue9 causing at least 300,000 deaths every year $\left.{ }^{[17,} 18\right]$. However, the official estimate of malaria episodes in Nigeria documented an average of four episodes per person per year $[6,19]$.

The frequency of antibodies against malaria parasites has been used as a means of assessing malaria infectivity ${ }^{[20-24]}$ and show potential to detect recent changes in plasmodium density. Several authors had earlier reported ${ }^{[25,26]}$ that it is more difficult to assess plasmodium density by the conventional malaria parasitemia determination during scanty infection or when mosquito numbers are low.

Previous authors also reported an association between decreased anti-MSP-1 antibodies and decreased risk of clinical malaria depending on the type of Fc $\gamma$ R IIa allele involved ${ }^{[27,28]}$ while others reported MSP-1 as a potential antigen for malaria vaccine preparation in the nearest future ${ }^{[29,30]}$.

The alarming rate of drug resistance against malaria infection has posed a major threat against effective anti-malarial preparations in endemic region ${ }^{[31-33]}$ therefore regular search for new anti- malaria preparations and vaccine remains a global priority.

The aim of this study was to determine the frequency of subjects with natural immunity against malaria and conduct serological and molecular analyses on their blood samples. It is expected that the findings in the study could serve as a useful guide for preparation of malaria vaccine or new anti-malaria preparations

\section{Materials and Methods}

\subsection{Sample collection and processing}

This study was conducted between August 2017 and September 2018 on one thousand two hundred and seventy $(1,270)$ apparently healthy volunteered students and workers within Owo and Ilorin communities aged 16-55 years. Six millilitres of the blood sample from each subject was collected, $2 \mathrm{ml}$ of which was put into EDTA container and properly mixed. $2 \mathrm{ml}$ was dispensed into heparinized bottle while the remaining $2 \mathrm{ml}$ was put in a plain container.

The 2ml-blood sample in EDTA container was used for thick malaria films preparation in duplicates. All the thick films were stained by Giemsa technique according to Chessbrough [34]. Only subjects tested negative for malaria parasite were further screened by serology. The $2 \mathrm{ml}-$ blood in each of the heparinized containers were used for molecular analysis while sera extracted from the blood samples kept in the plain containers were investigated for anti-MSP-1 antibody. All the sera from subjects were titrated and graded as low, moderate and high titer anti-merozoite sera.

\subsection{Selection criteria of subjects}

In the context of this study, an individual was considered to develop resistance against malaria infection if such subject has no history of malaria for over six months of exposure to the vector of the parasite, not sleeping under mosquito net and without taking any curative or prophylactic medication. In addition, the subjects must be tested negative for malaria parasitemia in peripheral blood by microscopy and record low level of MSP-1 antibody against Pf MSP-1 antigen. 


\subsection{Typing and titration of sample sera against Pf MSP-1 antigen}

The test cassette was removed from the foil pouch, and it was placed on a flat dry surface. Ten microliters of the serum was dropped in the hole on the cassette followed by 3 drops of the diluent. The reading was taken after 10 minutes and any positive result after ten minutes was disregarded. The test was recorded positive when both test and control produced pink lines within 10 minutes while the negative result was recorded when only the control line appeared within the same time. Serial dilution of sera was conducted with physiological saline followed by titration of the diluted sera with Pf MSP-1 antigen.

\subsection{Molecular Analysis}

Extraction of DNA from immune blood cells DNA was extracted from $2 \mathrm{ml}$ whole blood collected from each participant. The blood cell was washed in lysis buffer twice to exclude non-nucleated RBC, leaving nucleated WBC and platelets. The mixture was treated with RNase and proteinase $\mathrm{K}$ to digest RNA and protein impurities respectively form the cell lysis solution.

To the resultant mixture, protein precipitant was added to precipitate the protein impurities. The mixture was centrifuged and the supernatant decanted into propan-2-ol to precipitate DNA. The DNA pellet was washed in two changes of $70 \%$ alcohol, centrifuged and the DNA pellet dissolved in DNA hydration solution.

\subsection{DNA amplification using Allele-Specific PCR Primer}

The gene of interest was searched on Webbased Allele-Specific PCR Primer designing tool (WASP). This primer design tool was linked to the National centre for bioinformatics information (NCBI) where all genomic information were banked for research use. WASP automatically generates all existing alleles.

Parameters like primer length, melting temperature, product size range and selfcomplementarities were selected and the information was used to produce primer pairs for amplification of the Fc gamma receptor gene. A 96 - well plate was placed unto an ice bucket as the holder for the $0.2 \mathrm{ml}$ wall PCR tube. All PCR reagents were added unto cold $0.2 \mathrm{ml}$ thin-walled PCR tube to prevent nuclease activity and nonspecific priming. PCR reagents were added in the following order: $12.5 \mu \mathrm{l}$ of $1 \mathrm{X}$ dream Taq PCR

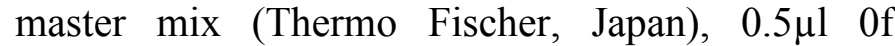
$10 \mu \mathrm{mol}$ of each primer and $1 \mu \mathrm{l}$ DNA. The mixture was made up to $25 \mu 1$ with nuclease-free water.

\subsection{Gel electrophoresis}

A total of $10 \mu \mathrm{L}$ of PCR product was loaded in each well, with $100 \mathrm{bp}$ ladder occupying the first well. The gels were allowed to run for 30 minutes at $120 \mathrm{~V}$ from negative to the positive electrode. After the period, the gel was placed on the UV transilluminator and observed for the bands of the amplicon. The negative control lane showed no visible bands. The picture of visible bands on the gel was finally taken and compared with respect to the ladder.

\subsection{Questionnaire administration}

Prior to blood sample collection, a questionnaire was administered to all the participants to assess their out-door exposure to mosquito, usage of mosquito nets, recent treatment with anti-malaria drugs and prophylaxis, frequency of malaria cases per participant per year and respondents' demographic factors. In some few cases of illiteracy, a structured interview was conducted in respondents' local languages. To ascertain the information supplied by the participants, their malaria status was regularly monitored by contact tracing over six months after providing the information.

\subsection{Statistical analyses}

Data obtained from the study were input into the computer and analysed with SPSS version 23 software (SPSS Inc, USA). Malaria distribution by microscopy and serology with respect to age and gender were subjected to analysis of variance (ANOVA). Odd ratio statistics was used to assess the distribution of Fc gamma receptor IIa alleles among malaria resistance individuals. The test for significance level was based on a $\mathrm{P}$ value less than 0.05 . 


\section{Results}

Figures 1 and 2 show the respondents' perceived frequency of malaria infection per year in relation to age and gender. Out of total 1270 subjects examined, 383(30.2) have malaria every 13months, while 461(36.3) subjects have malaria every 4- 6 months and 426 (33.5) every 7- 12 months. By gender consideration, on the overall 156 $(28.1 \%)$ male subjects and $465(34.7 \%)$ female subjects had malaria frequency at interval of 1-3 months in a year; $158(28.4 \%)$ males and 175 (24.5\%) females have malaria frequency every 4-6 months, while $242(43.5 \%)$ males and 74 (10.4\%) females have a frequency between 7-12 months

Table 1 shows the distribution of Plasmodium infection by microscopy and serology in relation to age. On the overall, the highest rate of malaria (33.5\%) by microscopy was recorded within the age group 26-35 years while the highest frequency of malaria immunity $(45.3 \%)$ was recorded within the 16 - 25 years age group. The least rate of malaria infection was documented within the same age bracket 16 - 25 years by serology and microscopy recording $325(38.2 \%)$ and $140(16.4 \%)$ respectively. Statistically by analysis of variance (ANOVA), the results showed no significant difference in malaria frequency by serology and microscopy methods with respect to age $(\mathrm{Tcal}=0.603177 ; \mathrm{P}>0.05)$.

Distribution of serum titer grades among malaria immune subjects in relation to age and gender is as depicted in Table 2. Out of the total 490 sera that were collected from the subjects that were resistant to malaria infection, 267(54.5\%), 48(9.8\%) and $175(35.7 \%)$ recorded low, moderate and high titer values respectively. The highest frequency of low titer $215(16.9 \%)$ was recorded within the age bracket 16-25 years while the least was recorded among age group 46 - 55years. Similarly, more low titer subjects were documented among the males $190(14.9 \%)$ than their female counterparts with $77(6.0 \%)$. However when the serum grading was subjected to statistical analysis by chi-square, the result showed that there was no significant difference in the distribution of titer grades in relation to age $($ Tcal $=0.1957 ; \mathrm{P}>0.05)$ and gender $($ Tcal $=0.3654 ; \mathrm{P}>0.05)$.

Table 3 shows the distribution of the $\mathrm{Fc}$ gamma receptor IIa alleles in malaria resistant and susceptible subjects with respect to the odd ratio at 95\% confidence interval. Using the Fisher Exact test, Odd ratio, result showed a significant difference in the distribution of the allele among the individuals. Homozygous allele R131 appears to confer higher protection on malaria resistant individuals than heterozygote allele $\mathrm{R} 131 \mathrm{H}$ going by the values of Odd Ratio $(\mathrm{OR}=0.18,95 \% \mathrm{CI}=$ 0.07-0.44), while homozygote allele $\mathrm{H} 131$ was slightly protective $(\mathrm{OR}=0.48,95 \% \mathrm{CI}=0.19-1.19)$

Table 4 depicts the frequencies of Fc $\gamma$ R IIa allele among malaria resistant and susceptible subjects. Out of 1270 subjects examined, 225 had homozygous R131 genotype; comprising $180(36.7 \%)$ malaria resistant and 45(5.6\%) susceptible subjects. 560 homozygous H131 genotype had 150 (30.6\%)malaria resistant and $410(52.6 \%)$ susceptible while a total of 485 heterozygote allele $\mathrm{R} 131 \mathrm{H}$ was recorded in the study of representing 160 (32.7\%)resistant and 325 $(41.7 \%)$ susceptible subjects. Statistically, no significant difference in the distribution of allele was recorded with respect to subjects' immunity against malaria $($ Tcal $=1.69, \mathrm{P}>0.05)$

Table 1: Frequency of malaria immunity in relation to age

\begin{tabular}{ccccc}
\hline Age (years) & $\begin{array}{c}\text { Number } \\
\text { Examined }\end{array}$ & $\begin{array}{c}\text { Microscopy } \\
\text { positive } \\
(\%)\end{array}$ & $\begin{array}{c}\text { Serology } \\
\text { positive } \\
(\%)\end{array}$ & $\begin{array}{c}\text { Subjects with } \\
\text { malaria immunity } \\
(\%)\end{array}$ \\
\hline $16-25$ & 850 & $140(16.4)$ & $325(38.2)$ & $385(45.3)$ \\
$26-35$ & 254 & $85(33.5)$ & $107(42.1)$ & $62(24.4)$ \\
$36-45$ & 120 & $31(25.8)$ & $57(47.5)$ & $32(26.7)$ \\
$46-55$ & 46 & $11(23.9)$ & $24(52.2)$ & $11(23.9)$ \\
\hline TOTAL & 1270 & $267(21.0)$ & $513(40.3)$ & $490(38.6)$ \\
\hline
\end{tabular}

Note: Immunity against malaria implies No signs, symptoms prophylaxis and treatment of malaria for at least six months, No malaria parasite in peripheral blood and positive for MSP-1 serology test. 
Table 2: Distribution of serum grades collected from subjects with immunity against malaria in relation to age and gender

Age group Number Examined

Frequency of malaria immune sera/Grade

Low High

$(\%)$

$(\%)$

$(\%)$

$16-25$

385

215(55.8)

20(5.1)

150(39.1)

$26-35$

62

26 (41.9)

16(25.8)

20(32.3)

$36-45$

32

17(53.1)

10(31.3)

$5(15.6)$

$46-55$

11

9(81.8)

2(18.2)

$0(0.00)$

Gender

Female

156

77(49.)

12(7.7)

67(42.9)

Male

334

190(56.9)

$36(10.8)$

108(32.3)

Total

490

267(54.5)

48(9.8)

175(35.7)

Table 3: Distribution of FcyR IIa alleles in malaria immune and susceptible subjects with respect to Odd Ratio analysis

\begin{tabular}{lccccc}
\hline Fc $\gamma$ R IIa genotype & Immune & Susceptible & $95 \%$ CI & P-value & Odd Ratio \\
R131 & 266 & 120 & $0.07-0.44$ & 0.001 & 0.18 \\
H131 & 121 & 329 & $0.19-1.19$ & 0.11 & 0.48 \\
R131H & 103 & 331 & $0.56-3.89$ & 0.96 & 1.00 \\
\hline
\end{tabular}

Table 4: Distribution of FcyR IIa allele among malaria resistant and susceptible subjects

\section{SUBJECTS EXAMINED WITH}

FcyR IIa genotype Mp Immunty (\%) No immunity (\%) Total

R131

H131

$\mathrm{R} 131 \mathrm{H}$

Total
$180(36.7)$

$150(30.6)$

$160(32.7)$

$490(38.6)$
$45(5.6)$

$410(52.6)$

$325(41.7)$

780(61.4)
225

560

485

1270 


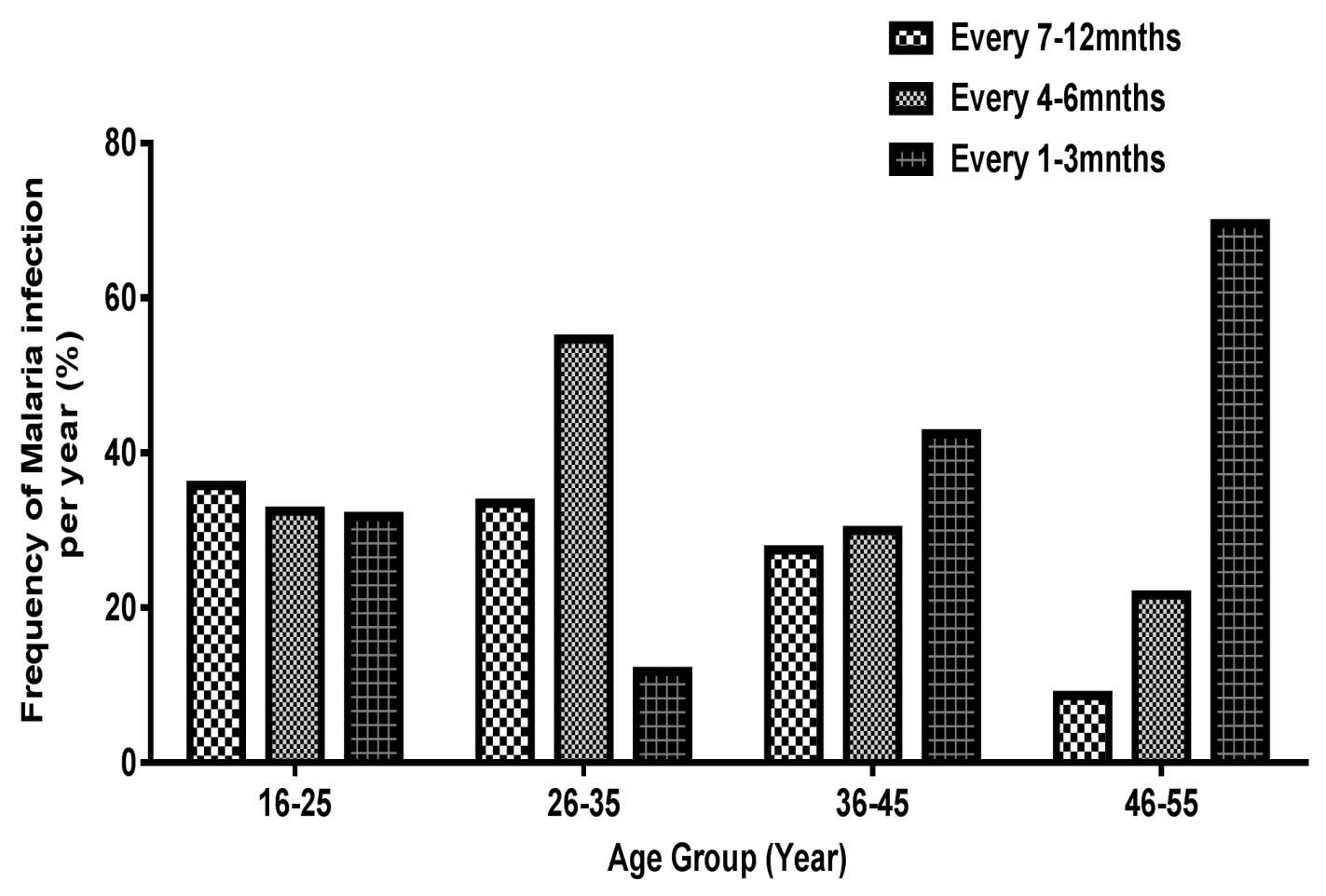

Figure 1: Respondents' perceived frequency of malaria infection in relation to age

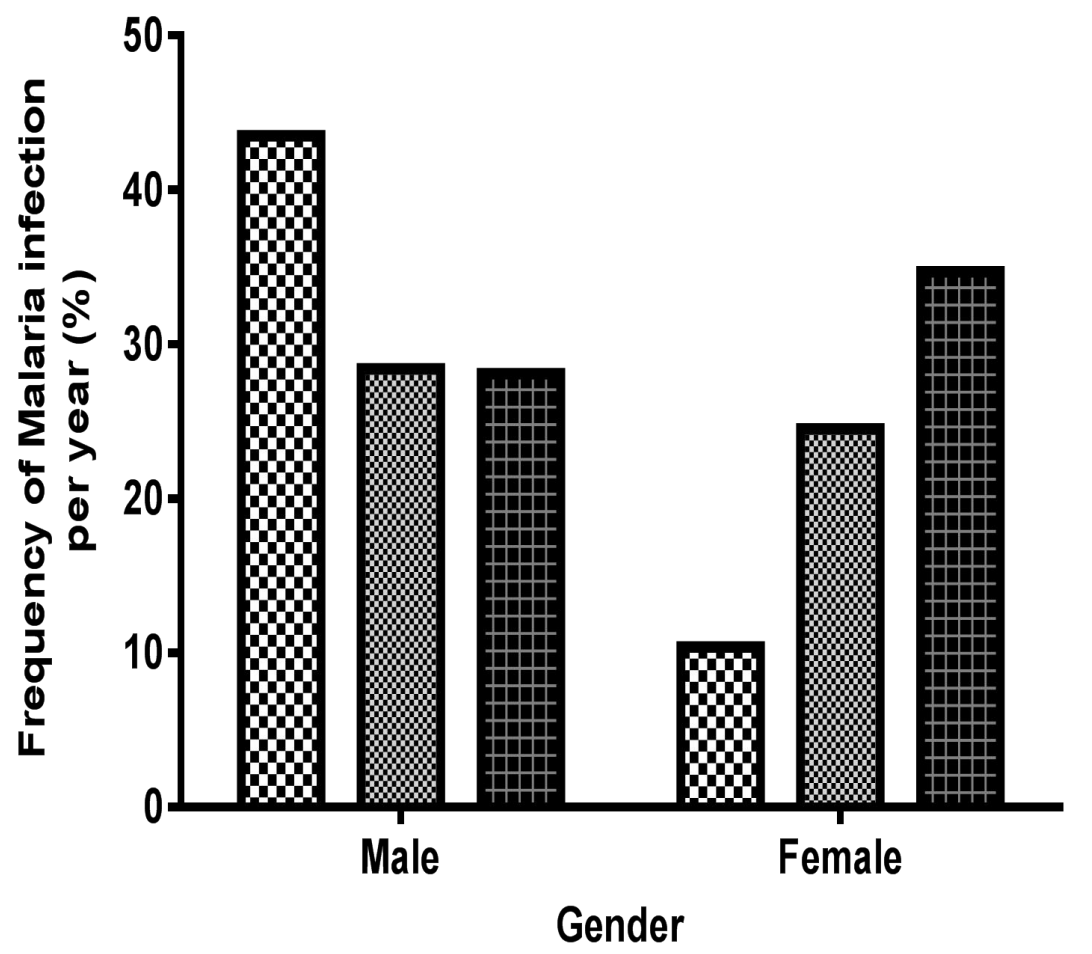

Every 7-12mnths

Every 4-6mnths

\#\# Every $1-3 \mathrm{mnths}$

Figure 2: Respondents' perceived frequency of malaria infection in relation to gender 


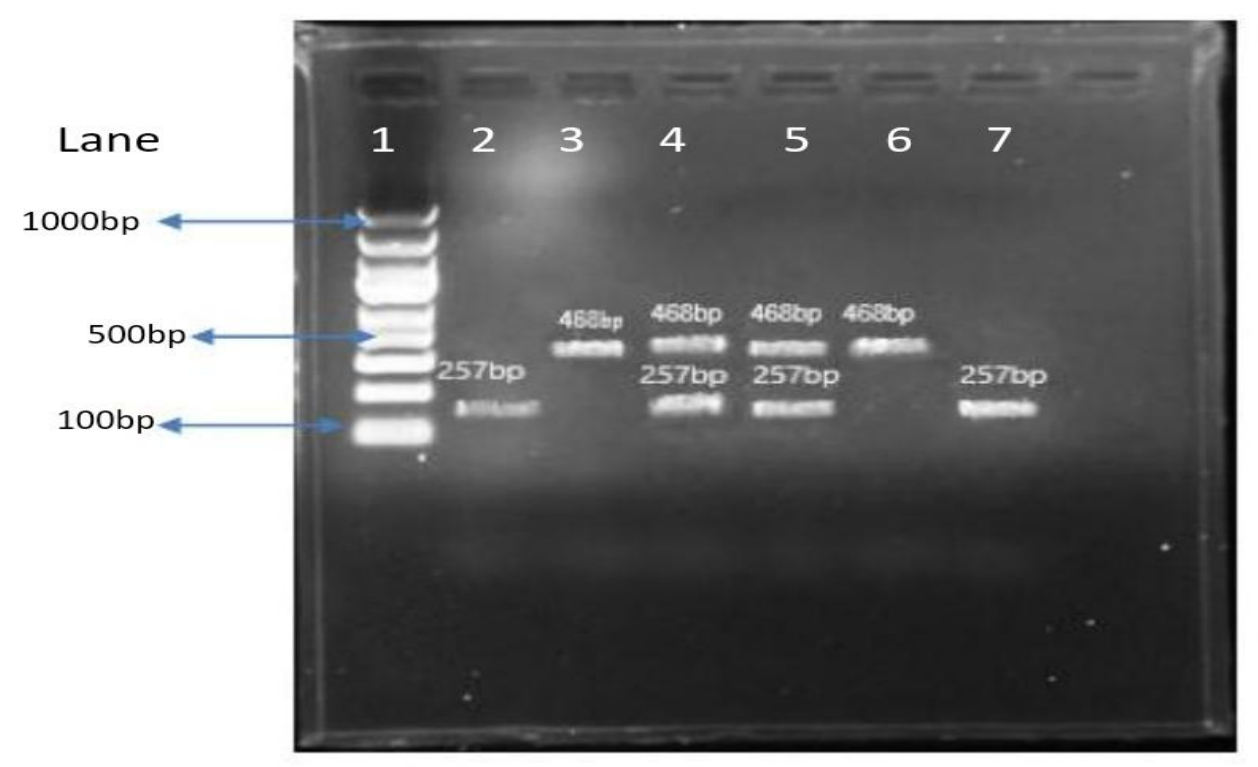

Figure 3: The Agarose gel picture showing gel bands of Gamma Receptor IIa alleles

Lane 1 represents the molecular weight marker, lanes 2 and lane 7 are bands for H/H131 (257bp), lanes 3 and 6 represent R/R131 band (468bp) while lanes 4 and 5 are the bands for Heterozygote allele R131H.

\section{Discussion}

On the overall, this study revealed $21.0 \%$ positive cases of malaria by microscopy while serology method reported it as $40.3 \%$. Although several studies ${ }^{[20-26]}$ have alluded to the efficacy of plasmodium antibody detection as an acceptable method of assessing the frequency of malaria infection, however the disparity between the gold standard microscopy and serology in the present study is worrisome. The reason for the higher result by serology could probably be attributed to the fact that antibody against an antigen could still be detectable long time after total clearance of the infection thereby producing false positive result $[35$, 38].

In spite of the high rate of malaria infection in this study, $21.0 \%$ of the subjects investigated still developed resistance to the infection even with regular exposure to the causative vector of the infection. A subject was considered to develop resistance against malaria infection if the subject has no history of malaria for over six months of exposure to the vector of the parasite, not sleeping under mosquito net and without taking any curative or prophylactic medication. In addition, the subjects were tested negative for malaria parasitemia in peripheral blood by microscopy but recorded low level antibody against Pf MSP-1 antigen. Our finding therefore agrees with the previous studies ${ }^{[29}$ ${ }^{30]}$ that documented MSP-1 as a potential antigen for malarial vaccine

According to findings from some previous studies ${ }^{[27,28]}$, the lower the titer level of ant-MSP-1 in a subject, the less the risk of clinical malaria. Therefore, the reactivity of the sera of the study subjects were categorized into high, moderate and low grades of antibody titers against MSP-1 antigen. Assessing the distribution of low titer of antiMSP-1 (Titers=2-4) in relation to age and gender, the highest frequency $215 / 1270(16.9 \%)$ was recorded within the age bracket 16-25 years. Our study also observes that as the age increases, the occurrence of low titer reduces implying that malaria immunity reduces with age. Similarly, low titer sera were more frequently documented among the males $(14.9 \%)$ than their female counterparts with $6.0 \%$. 
Although a slightly higher prevalence of R131 was recorded in the study, there was no significant difference in the distribution of Fc $\gamma$ R IIa allele with respect to subject immunity to malaria. The finding is in agreement with those previously reported $[39,40]$. However, our finding differs from the results of research conducted in Mali by Maiga and his Associates ${ }^{[41,42]}$ in which $\mathrm{H} / \mathrm{H} 131$ allele recorded a significantly higher frequency. The variation could be attributed to the difference in the age of the sampled populations in both studies. While we investigated apparently healthy adults, both children and adults were included in the study in Mali. Also, the variation could be attributed to the fact that our study was carried out on the general population and not on a selected ethnic group like the Dogo and Fulani that may be genetically homogeneous in nature. The study revealed that individuals with resistance against malaria recorded a higher frequency $(36.7 \%)$ of homozygous allele R131 while the predominant allele in subjects susceptible to malaria was $\mathrm{R} 131 \mathrm{H}$ with the frequency of $67.3 \%$. Analysis of variance showed a significant variation in the distribution of Fc $\gamma$ R IIa allele between malaria resistant subjects and those that were susceptible to malaria. (Tcal $=3.431 ; \mathrm{P}$ $<0.05)$. The malaria susceptible subjects also recorded a higher frequency of the heterozygote allele R131H of $75.8 \%$.

Judging the relationship between the distribution of allele among subjects with immunity against malaria and calculated odds ratio, significantly higher level was recorded in genotype R131 than other alleles. This implies that homozygous allele R131 is capable of conferring higher immunity on individuals against malaria better than heterozygote allele $\mathrm{R} 131 \mathrm{H}$ going by the values of Odd Ratio $(\mathrm{OR}=0.18,95 \% \mathrm{CI}=0.07-0.44)$, while homozygote allele $\mathrm{H} 131$ was slightly protective $(\mathrm{OR}=0.48,95 \% \mathrm{CI}=0.19-1.19)$. Our present findings are in consonance with the results documented by previous authors [43, 44]. However other researchers observed that the $131 \mathrm{R} / \mathrm{R}$ genotype was associated with susceptibility to severe malarial anaemia and various grades of malaria ${ }^{[45,46]}$.

\section{Conclusion and recommendation}

Although the study was conducted in the malaria-endemic area, surprisingly the finding showed that $21.0 \%$ of the sampled population were resistant to malaria infection. The clinical implication of these findings is that some individuals in this locality are genetically and immunologically protected against malarial infection. Therefore, further studies on the specific genes and immunoglobulin responsible for the uniqueness in such individuals are recommended, as these can serve as baseline information for the development of malaria vaccine candidate or new anti-malaria preparations in the nearest future.

\section{Authors contributions}

The research was conceptualized and designed by AAA. Co-researchers SOJ, TDA and SAN reviewed the research proposal, conducted the research, collated, organized and analysed the data. AAA supervised the research methodology and data analysis. The initial draft of the article was jointly written by SOJ, TDA and SAN while the corrected version was prepared by AAA. Final manuscript was collectively reviewed and approved by all authors

\section{Ethical approval and statement}

We affirm that this work was approved by Ethical and Animal Care Committee of School of Basic Medical Sciences, Kwara State University Malete, Nigeria with Reference Number $\mathrm{KW} / \mathrm{SBMS} / \mathrm{ERC} / 115$ and that the study was conducted on the human subjects in accordance with code of ethics of World Medical Association (Helsinki declaration of 1975 and revised in 2008).

\section{Conflict of interest and funding}

All authors of this manuscript have unanimously agreed to publish it in American Journal of Biomedical Sciences if ultimately accepted. We also affirm that the work has not been presented in any form or sent to any journal for publication. This study is self-sponsored and has not 
attracted grant from funding organizations in the private or public sectors

\section{Acknowledgement}

We are grateful to Mrs Adijat Anifowose, the Secretary to the Faculty of Allied Health Sciences, University of Medical Sciences, Ondo, Nigeria for typing the manuscript of this article.

\section{References}

1 World Health Organization (WHO). United Nation Children's Fund and Roll Back Malaria. 2005 World malaria report, 2005

2 Hay SI, Okiro EA, Gething PW, Patil AP, Tatem AJ, Guerra CA, Snow RW. Estimating the global clinical burden of Plasmodium falciparum malaria in 2007. PLoS Med 2010; 7(6): e1000290 DOI: 10.1371/journal.pmed.1000290

3 Onah, I. E.; Adesina, F. P.; Uweh, P. O.; Anumba, J. Challenges of Malaria Elimination in Nigeria; A Review. Int J Infectious Dis Therapy 2017; 2(4): 79-85 DOI: 10.11648/j.ijidt.20170204.14

4 Gething PW, Patil AP, Smith DL, Guerra CA, Elyazar IR, Johnston GL, Tatem AJ, Hay SI. A new world malaria map: Plasmodium falciparum endemicity in 2010. Malar $\boldsymbol{J}$ 2011; 10: 378 DOI: $10.1186 / 1475-2875-10-378$

5 "Economic costs of malaria".Roll Back Malaria WHO partnership,World Health Organization (WHO).2003.

6 Egbuche, C. M. ; Eneanya, C. I. ; Aribodo, D. N.; Eneaya, O. A.; Ogbuagu, C. N.; EzugboNwobi, I. K. Malaria prevalence and use of insecticide-treated net among communities in Aguleri, Anambra State, Nigeria. Bioscientist, 2013; 1: $60-66$.

7 Ngum, H. N.; Serophine, V. Assessing the effective use of mosquito nets in the prevention of malaria in some parts of Mezam division, Northwest Region Cameroon. Malar J 2016; 15(1): 390.

8 Nmadu, P. M.; Peter, E.; Alexander, P.; Koggie, A. Z.; Maikenti, J. I. The Prevalence of Malaria in Children between the Ages 2-15 Visiting Gwarinpa General Hospital Life-
Camp, Abuja, Nigeria. J Health Sci 2015; 5(3): 47-51.

9 Dawaki S, Al-Mekhlafi HM, Ithoi I, Ibrahim J, Atroosh WM, Abdulsalam AM, Sady H, Elyana FN, Adamu AU, Yelwa SI, Ahmed A, Al-Areeqi MA, Subramaniam LR, Nasr NA, Lau YL. Is Nigeria winning the battle against malaria? Prevalence, risk factors and KAP assessment among Hausa communities in Kano State. Malar $\boldsymbol{J}$ 2016; 15: 351 DOI: 10.1186/s12936-016-1394-3

10 National Population Commission (NPC). National Malaria Control Programme (NMCP) Nigeria and ICF International. Nigeria Malaria Indicator Survey 2010

11 Onasoga, O. A.; Afolayan, J. A.; Olubiyi, S. K.; Yusuf, A. G.; Rotimi, F. E. Methods employed in the prevention and treatment of malaria among pregnant women in a riverine community in Bayelsa State, Nigeria. The Nig Health J 2016; 16 (3): 6-10.

12 Murray CJ, Rosenfeld LC, Lim SS, Andrews $\mathrm{KG}$, Foreman KJ, Haring D, Fullman $\mathrm{N}$, Naghavi M, Lozano R, Lopez AD. Global malaria mortality between 1980 and 2010: a systematic analysis. Lancet 2012; 379(9814): 413-431 DOI: 10.1016/S0140-6736(12)60034$\underline{8}$

13 Kokwaro G. Ongoing challenges in the management of malaria. Malar $\boldsymbol{J} 2009$; 8 Suppl 1: S2 DOI: 10.1186/1475-2875-8-S1-S2

14 Dalaba MA, Welaga P, Oduro A, Danchaka LL, Matsubara C. Cost of malaria treatment and health seeking behaviour of children under-five years in the Upper West Region of Ghana. PLoS One 2018; 13(4): e0195533 DOI: 10.1371/journal.pone.0195533

15 Etusim, P. E.; Kalu, C.; Nduka, F. O.; Kalu, E. C.; Melariri, P. E.; Nwoke, M.; Aduaka, A. C. Studies on the Prevalence of Malaria Parasite among Children with Splenomegaly in Aba Metropolis, Abia State, Nigeria. J Med Applied Biosci 2013; 5(1): 56-66.

16 Olupot-Olupot P, Maitland K. Management of severe malaria: results from recent trials. $\boldsymbol{A d v}$ Exp Med Biol 2013; 764: 241-250 DOI: 10.1007/978-1-4614-4726-9 20

17 Kyu HH, Georgiades K, Shannon HS, Boyle $\mathrm{MH}$. Evaluation of the association between 
long-lasting insecticidal nets mass distribution campaigns and child malaria in Nigeria. Malar J 2013; 12: 14 DOI: 10.1186/1475-2875-12-14

18 Adigun AB, Gajere EN, Oresanya O, Vounatsou P. Malaria risk in Nigeria: Bayesian geostatistical modelling of 2010 malaria indicator survey data. Malar $\boldsymbol{J}$ 2015; 14: 156 DOI: $10.1186 / \mathrm{s} 12936-015-0683-6$

19 Alaba, O. A.; Alaba, O. B. Malaria in Rural Nigeria: Implications for the Millennium Development Goals. Afri Dev Review 2009; 21(1): $\quad 73-85 \quad$ DOI: $\quad \underline{10.1111 / \mathrm{j} .1467-}$ $\underline{\text { 8268.2009.00204.x }}$

20 Corran P, Coleman P, Riley E, Drakeley C. Serology: a robust indicator of malaria transmission intensity? Trends Parasitol 2007; 23(12): $\quad 575-582 \quad$ DOI: 10.1016/j.pt.2007.08.023

21 Drakeley CJ, Corran PH, Coleman PG, Tongren JE, McDonald SL, Carneiro I, Malima R, Lusingu J, Manjurano A, Nkya WM, Lemnge MM, Cox J, Reyburn H, Riley EM. Estimating medium- and long-term trends in malaria transmission by using serological markers of malaria exposure. Proc Natl Acad Sci USA 2005; 102(14): 5108-5113 DOI: 10.1073/pnas.0408725102

22 Greenhouse B, Ho B, Hubbard A, NjamaMeya D, Narum DL, Lanar DE, Dutta S, Rosenthal PJ, Dorsey G, John CC. Antibodies to Plasmodium falciparum antigens predict a higher risk of malaria but protection from symptoms once parasitemic. J Infect Dis 2011; 204(1): 19-26 DOI: 10.1093/infdis/jir223

23 Bousema T, Youssef RM, Cook J, Cox J, Alegana VA, Amran J, Noor AM, Snow RW, Drakeley C. Serologic markers for detecting malaria in areas of low endemicity, Somalia, 2008. Emerg Infect Dis 2010; 16(3): 392-399 DOI: $10.3201 /$ eid1603.090732

24 Kusi KA, Bosomprah S, Kyei-Baafour E, Dickson EK, Tornyigah B, Angov E, Dutta S, Dodoo D, Sedegah M, Koram KA. Seroprevalence of Antibodies against Plasmodium falciparum Sporozoite Antigens as Predictive Disease Transmission Markers in an Area of Ghana with Seasonal Malaria Transmission. PLoS One 2016; 11(11): e0167175 DOI: 10.1371/journal.pone.0167175
25 Kusi KA, Bosomprah S, Dodoo D, KyeiBaafour E, Dickson EK, Mensah D, Angov E, Dutta S, Sedegah M, Koram KA. Antisporozoite antibodies as alternative markers for malaria transmission intensity estimation. Malar J 2014; 13: 103 DOI: 10.1186/14752875-13-103

26 Bretscher MT, Supargiyono S, Wijayanti MA, Nugraheni D, Widyastuti AN, Lobo NF, Hawley WA, Cook J, Drakeley CJ. Measurement of Plasmodium falciparum transmission intensity using serological cohort data from Indonesian schoolchildren. Malar $\boldsymbol{J}$ 2013; 12: 21 DOI: $10.1186 / 1475-2875-12-21$

27 Fowkes FJ, Richards JS, Simpson JA, Beeson JG. The relationship between anti-merozoite antibodies and incidence of Plasmodium falciparum malaria: A systematic review and meta-analysis.PLoS Med 2010;7(1): e1000218 DOI: $10.1371 /$ journal.pmed.1000218

28 Stewart L, Gosling R, Griffin J, Gesase S, Campo J, Hashim R, Masika P, Mosha J, Bousema T, Shekalaghe S, Cook J, Corran P, Ghani A, Riley EM, Drakeley C. Rapid assessment of malaria transmission using agespecific sero-conversion rates.PLoS One 2009; 4(6): e6083

DOI: 10.1371/journal.pone.0006083

29 Moritz, T.; Sonja, Z.; Susann, H. A.; Cabrera, N. S.; Struck, N. S. Functional Analysis of the Leading Malaria Vaccine Candidate AMA-1 Reveals an Essential Role for the Cytoplasmic Domain in the Invasion Process. PLos Pathog. 2009; 100032.

30 Hill AV. Vaccines against malaria. Philos Trans R Soc Lond B Biol Sci 2011; 366(1579): 2806-2814 DOI: $10.1098 /$ rstb.2011.0091

31 Barnes KI, White NJ. Population biology and antimalarial resistance: The transmission of antimalarial drug resistance in Plasmodium falciparum. Acta Trop 2005; 94(3): 230-240 DOI: $10.1016 /$ j.actatropica.2005.04.014

32 Abubakar,A. A.;Kolawole, D. O.; Babatunde, S. K.; Sunday, O.; Ameen, N. Investigation of anti-plasmodium activity of a combined extract of Bryophyllum pinnatum and Aloe barbadensis leaves. Int J Sci Nat 2014; 5(1): 67-70. 
33 Ridley RG. Plasmodium: drug discovery and development--an industrial perspective. Exp Parasitol 1997; 87(3): 293-304 DOI: 10.1006/expr.1997.4230

34 Cheesbourgh, M. District Laboratory Practice in Tropical Countries, 2nd ed. Cambridge University Press: Cambridge, 2005.

35 Woods CR. False-Positive Results for Immunoglobulin $\mathrm{M}$ Serologic Results: Explanations and Examples. J Pediatric Infect Dis Soc 2013; 2(1): 87-90 [PMID: 26619450 DOI: $10.1093 /$ jpids/pis133]

36 Berth M, Bosmans E. Acute parvovirus B19 infection frequently causes false-positive results in Epstein-Barr virus- and herpes simplex virus-specific immunoglobulin $M$ determinations done on the Liaison platform. Clin Vaccine Immunol 2009; 16(3): 372-375 DOI: 10.1128/CVI.00380-08

37 Ismail AA, Ismail AA, Ismail Y. Probabilistic Bayesian reasoning can help identifying potentially wrong immunoassays results in clinical practice: even when they appear 'notunreasonable'. Ann Clin Biochem 2011; 48(Pt 1): 65-71 DOI: $10.1258 /$ acb.2010.010197

38 Centers for Disease C, Prevention. Falsepositive results with a commercially available West Nile virus immunoglobulin $\mathrm{m}$ assay United States, 2008. MMWR Morb Mortal Wkly Rep 2009; 58(17): 458-460

39 Israelsson E, Vafa M, Maiga B, Lysen A, Iriemenam NC, Dolo A, Doumbo OK, TroyeBlomberg $\mathrm{M}$, Berzins $\mathrm{K}$. Differences in Fcgamma receptor IIa genotypes and IgG subclass pattern of anti-malarial antibodies between sympatric ethnic groups in Mali. Malar $\boldsymbol{J}$ 2008; 7: 175 DOI: 10.1186/14752875-7-175

40 Cherif MK, Sanou GS, Maiga B, Israelsson E, Ouedraogo AL, Bougouma EC, Diarra A, Ouedraogo A, Ouattara AS, Troye-Blomberg M, Dolo A, Cavanagh DR, Theisen M, Modiano D, Sirima SB, Nebie I. FcgammaRIIa polymorphism and anti-malaria-specific IgG and $\operatorname{IgG}$ subclass responses in populations differing in susceptibility to malaria in Burkina Faso. Scand J Immunol 2012; 75(6): 606-613 DOI: $10.1111 / \mathrm{j} .1365-3083.2012 .02690 . \mathrm{x}$
41 Nasr, A.; Iriemenam, N. C.; Troye-Blomberg, M.; Giha, H. A.; Balogun, H. A.; Osman, O. F.; Montgomery, S. M.; ElGhazal, G.; Berzins, K. Fc gamma Receptor IIa (CD32) Polymorphism and Antibody responses to Asexual Bloodstage Antigens of Plasmodium falciparum Malaria in Sudanese Patients. Scand $J$ Immunol 2007; 66: 87 - 96

42 Maiga B, Dolo A, Toure O, Dara V, Tapily A, Campino S, Sepulveda N, Corran P, Rockett K, Clark TG, Blomberg MT, Doumbo OK. Fc gamma receptor IIa-H131R polymorphism and malaria susceptibility in sympatric ethnic groups, Fulani and Dogon of Mali. Scand $J$ Immunol 2014; 79(1): 43-50 DOI: $\underline{10.1111 / \text { sji.12122 }}$

43 Shi YP, Nahlen BL, Kariuki S, Urdahl KB, McElroy PD, Roberts JM, Lal AA. Fcgamma receptor IIa (CD32) polymorphism is associated with protection of infants against high-density Plasmodium falciparum infection. VII. Asembo Bay Cohort Project. J Infect Dis 2001; 184(1): 107-111 [PMID: 11398118 DOI: 10.1086/320999]

44 Ouma C, Keller CC, Opondo DA, Were T, Otieno RO, Otieno MF, Orago AS, Ong'Echa JM, Vulule JM, Ferrell RE, Perkins DJ. Association of FCgamma receptor IIA (CD32) polymorphism with malarial anemia and highdensity parasitemia in infants and young children. Am J Trop Med Hyg 2006; 74(4): 573-577 [PMID: 16606986]

45 Ogoe, B. M.;Wilson, M. D.; Yaa, O. D.; Rogers, W.; Brown, C. A.; Adu, D. Studies on the allotypic variants of IgG receptors Fc gamma RIIA and Fc gamma IIIb and their association with severe clinical malaria among Ghanaian children. Third MIM Pan-Afr Malaria Conf, 2002, Abstract no: 166 p. 116.

46 Nasr A, Hamid O, Al-Ghamdi A, Allam G. Anti-malarial IgG subclasses pattern and FcgammaRIIa (CD32) polymorphism among pregnancy-associated malaria in semi-immune Saudi women. Malar $\boldsymbol{J}$ 2013; 12: 110 DOI: $\underline{10.1186 / 1475-2875-12-110}$ 